\title{
Investigation of Combustion Control in a Dump Combustor Using the Feedback Free Fluidic Oscillator
}

\author{
Eric J. Meier* \\ Purdue University, West Lafayette, IN, 47907, USA \\ Matthew J. Casiano ${ }^{\dagger}$ \\ NASA Marshall Space Flight Center, Huntsville, AL, 35812, USA \\ William E. Anderson ${ }^{\ddagger}$ and Stephen D. Heister ${ }^{\S}$ \\ Purdue University, West Lafayette, IN, 47907, USA
}

\begin{abstract}
A feedback free fluidic oscillator was designed and integrated into a single element rocket combustor with the goal of suppressing longitudinal combustion instabilities. The fluidic oscillator uses internal fluid dynamics to create an unsteady outlet jet at a specific frequency. An array of nine fluidic oscillators was tested to mimic modulated secondary oxidizer injection into the combustor dump plane. The combustor has a coaxial injector that uses gaseous methane and decomposed hydrogen peroxide with an overall $\mathrm{O} / \mathrm{F}$ ratio of 11.7. A sonic choke plate on an actuator arm allows for continuous adjustment of the oxidizer post acoustics enabling the study of a variety of instability magnitudes. The fluidic oscillator unsteady outlet jet performance is compared against equivalent steady jet injection and a baseline design with no secondary oxidizer injection. At the most unstable operating conditions, the unsteady outlet jet saw a $67 \%$ reduction in the instability pressure oscillation magnitude when compared to the steady jet and baseline data. Additionally, computational fluid dynamics analysis of the combustor gives insight into the flow field interaction of the fluidic oscillators. The results indicate that open loop high frequency propellant modulation for combustion control can be achieved through fluidic devices that require no moving parts or electrical power to operate.
\end{abstract}

\section{Introduction}

Combustion instabilities resulting in high frequency and high amplitude pressure oscillations within the combustion chamber continue to plague rocket and gas turbine designers. Combustion instabilities which arise from the coupling between unsteady heat release and chamber acoustics, can lead to reduced performance and even catastrophic failure due to the pressure oscillations and increased heat transfer. Historically, instabilities have been mitigated through extensive experimental testing and hardware changes until a stable design is developed which can be expensive and extend development time. ${ }^{1}$ To avoid costly delays associated with instabilities, research has focused on both the prediction of instabilities early in the design phase and combustion control through both passive and active control systems. Combustion control methods offer the ability to stabilize an unstable combustor with minimal design changes to the existing engine design.

Many active instability control techniques use mechanical or acoustic means to disrupt the coupling between the heat release and chamber acoustics. The most common active control methods use either high speed valving or acoustic waves from a speaker to modulate either the fuel flow, oxidizer flow, or both propellants. This method works to control the buildup of unburned propellants that contribute to periodic heat release. ${ }^{2}$ Other active control methods include, but are not limited to; variable geometry, ${ }^{3}$ secondary fuel injection, ${ }^{4-7}$ high velocity air jets, ${ }^{8-11}$ and arrays of micro

\footnotetext{
${ }^{*}$ Graduate Student, School of Aeronautics and Astronautics, 500 Allison Rd., West Lafayette, IN 47907, and AIAA Student Member.

${ }^{\dagger}$ Acoustics and Stability Engineer, Fluid Dynamics Branch, MSFC, Huntsville, AL 35812 , and AIAA Senior Member.

†Professor, School of Aeronautics and Astronautics, 500 Allison Rd., West Lafayette, IN 47907, and AIAA Associate Fellow.

${ }^{\S}$ Professor, School of Aeronautics and Astronautics, 500 Allison Rd., West Lafayette, IN 47907, and AIAA Fellow.
} 
actuators. ${ }^{12}$ Active combustion control can be implemented in either an open loop or closed loop control system. Open loop control systems provide control based on set input conditions while closed loop control systems take information from current combustor operating conditions such as pressure, and adapt the control frequencies, magnitude, and/or phase to suppress the combustion instability.

In addition to primary propellant flow modulation, secondary injection of both steady and modulated jets of fuel or air have proven effective in controlling combustion instabilities. While this technique is not widely demonstrated in rocket combustors, research has demonstrated its effectiveness in premixed gas turbine combustors, working in both closed and open loop operation. Although closed loop control of secondary modulated injection has been shown to be more effective, open loop systems are much simpler and reliable to implement. ${ }^{13,14}$ Secondary injection generally involves modulating a small fraction (2-10\%) of the total fuel flow and injecting the modulated flow near the combustion zone. ${ }^{15}$ Air jets have also been implemented in secondary injection applications with the goal of stabilizing the flame anchoring position. ${ }^{16}$

Passive instability control techniques require no power or moving parts to operate. They are generally tailored to a specific combustor at a set operating condition for the best effectiveness since passive control cannot adapt to changing combustion environments. ${ }^{17}$ Passive control techniques include adjustments to injector geometry such as asymmetric propellant injection and baffles, addition of acoustic cavities, adjustments to the flame location, and geometric changes to control the combustion time lag. ${ }^{2,3,18-20}$ While passive techniques are limited in their effectiveness over a range of combustor operating conditions, they are attractive due to their simplicity and reliability. ${ }^{21}$

Looking closer at propellant modulation studies, ${ }^{22-29}$ the modulation methods, propellants, and injectors vary, but all the studies see a reduction in combustion instabilities due to the oscillatory propellant flow decoupling the pressure oscillations and heat release. Fluidic oscillators use internal fluid dynamics to create an oscillatory outlet jet and require no moving parts, making them an ideal candidate to replicate propellant flow modulation without the power consumption and reliability concerns associated with high speed valving and acoustic modulation. Fluidic oscillators have the potential to mimic the active open loop control performance, but with the reliability of a passive control system.

The feedback free fluidic oscillator, first developed by Raghu in 2001, uses the internal fluid dynamics of two impinging jets to create a single oscillatory sweeping outlet jet at a specific frequency as shown in Figure $1 .^{30}$ The feedback free fluidic oscillator works at frequencies as low as a few hundred hertz with liquids to over $20 \mathrm{kHz}$ with gaseous fluids with the frequency depending on the geometry, fluid type and density, and the operating pressure ratio. ${ }^{31-35}$ Building off of the previously discussed open loop control experiments which found that propellant modulation at frequencies away from the chamber acoustic harmonics suppressed combustion instabilities, the feedback free fluidic oscillator can be tailored to specific frequencies for open loop combustion instability control. This paper describes an experimental study using the feedback free fluidic oscillator for oxidizer flow control to assess performance of the fluidic oscillator. Results are discussed along with hardware configuration including manufacturing of the fluidic oscillator injector elements.

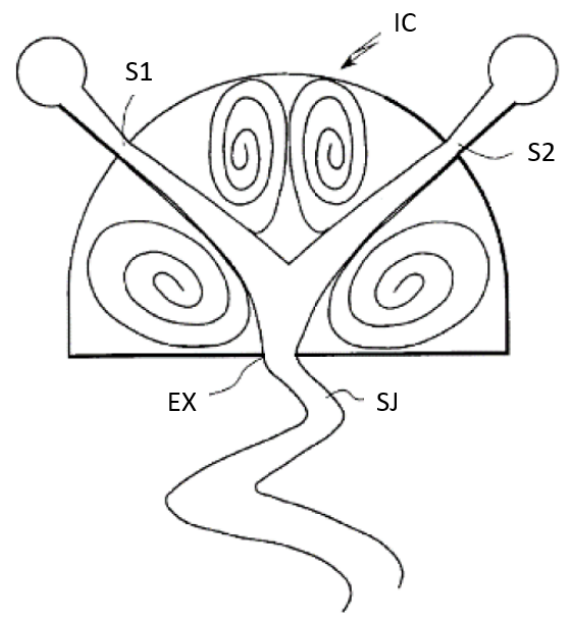

Figure 1. Illustration of the feedback free fluidic oscillator with internal vortical structures and oscillating outlet jet. ${ }^{30}$ 


\section{Experimental Setup}

The fluidic oscillator injector components were integrated into the Continuously Variable Resonance Combustor or CVRC as shown in Figure 2. The CVRC is a spontaneously unstable single element shear-coaxial dump combustor that uses methane gas and decomposed $90 \%$ hydrogen peroxide as the propellants with an overall $\mathrm{O} / \mathrm{F}=11.7 .^{36-39}$ Combustion chamber acoustics can be adjusted dynamically during a test by moving the actuator arm with the oxidizer choke plate attached at the end. The actuator arm moves the oxidizer post sonic boundary condition and adjusts the acoustic frequency within the oxidizer post, which can have a coupling effect with the combustion chamber acoustics leading to high amplitude combustion instabilities. This allows for testing a variety of combustion instability conditions while maintaining the same combustion chamber configuration and propellant flow rates.

The actuator used is a Parker ET Series ET050B02 electromechanical actuator controlled by a Parker Gemini GV6K servo drive/controller. ${ }^{40}$ High frequency pressure measurements, gathered at a rate of $100 \mathrm{kHz}$, were made using Kulite pressure transducers, model numbers: WCTV-312M-1000A and WCT-312M-70BARA. These pressure transducers were placed at several locations along the test article as indicated by Figure 2. In addition to the high frequency instrumentation, several low frequency pressure transducers and Type $\mathrm{K}$ thermocouples sampled at $500 \mathrm{~Hz}$ were placed throughout the test article to monitor system operating conditions.

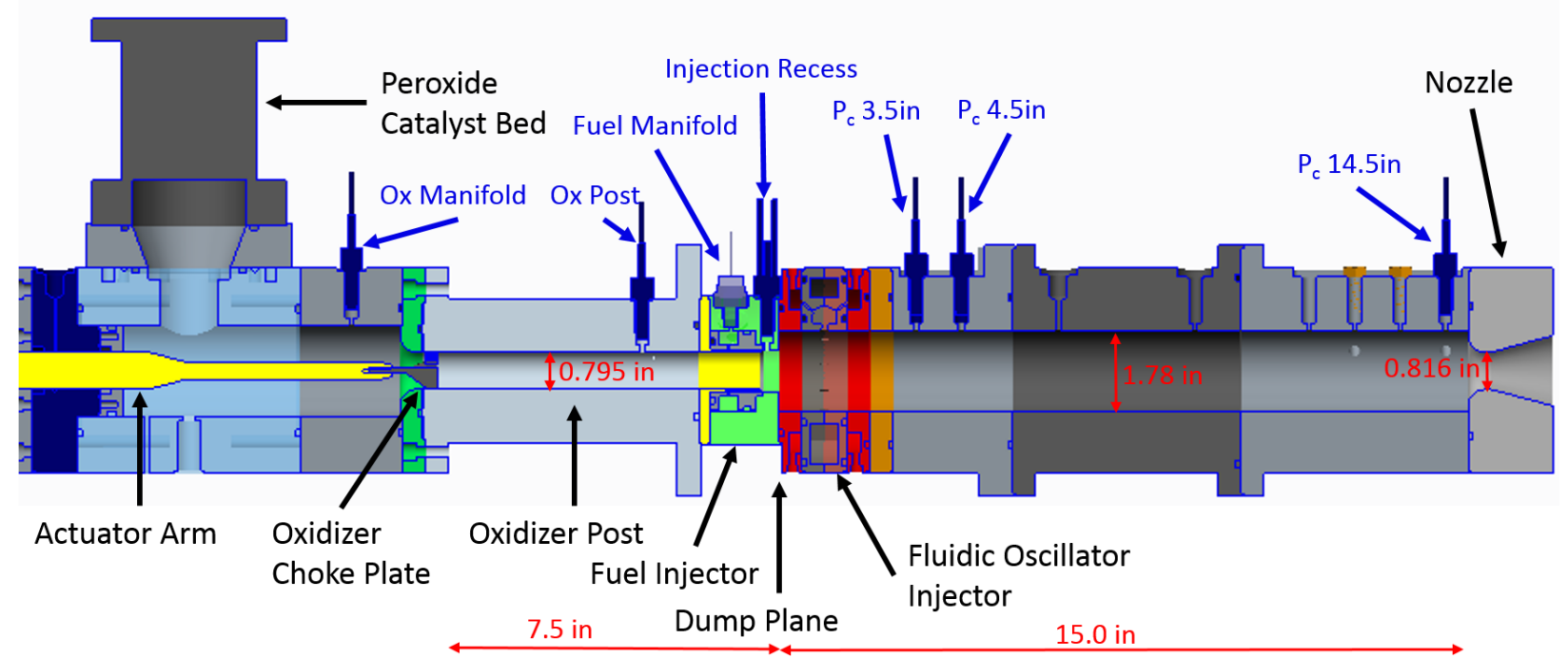

Figure 2. The fluidic oscillators were integrated downstream of the CVRC dump plane. High frequency pressure measurement locations are shown in blue, major components are shown in black, and major dimensions are shown in red. For additional dimensions, refer to reference ${ }^{41}$ appendix $C$.

The fluidic oscillator injector array consists of nine individual oscillators surrounding the combustion chamber dump plane. The nine oscillators are fed through common manifolds on either side to provide uniform operation. Two fluidic oscillator designs were manufactured with one producing a high frequency sweeping outlet jet and the other producing a steady jet while keeping the overall cavity volume the same. The two designs allowed for evaluation of the influence of the secondary injection itself and provided a means to assess the unique effect of the oscillating jet frequency through comparison to the steady jet. The constant cavity volume between the two designs maintained the combustion chamber acoustics as these injectors can act as resonators within the chamber. Figure 3 illustrates two-dimensional computational fluid dynamics, 2-D CFD, results for both the oscillating jet design, Figure 3a, and the steady jet design, Figure $3 b$. 


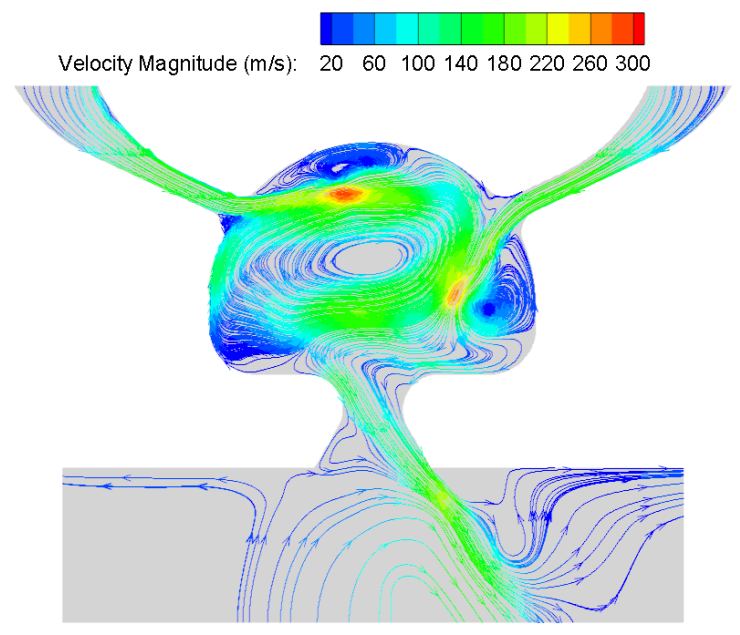

(a) High Frequency Sweeping Jet Design

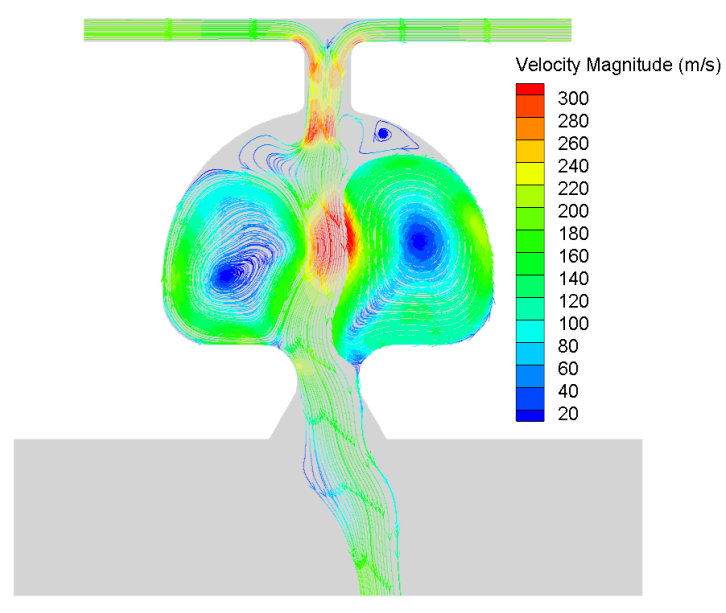

(b) Steady Outlet Jet Design

Figure 3. Two dimensional CFD results show the internal flow streamlines for the steady and oscillating fluidic injector designs.

The fluidic oscillator injector components, including the fluidic oscillator array and two manifolds on either side to feed the oscillators, were integrated downstream of the combustor dump plane to provide unsteady controlled mixing and combustion. The experimental setup allows for either high pressure nitrogen gas or a portion of the decomposed hydrogen peroxide from the main oxidizer flow to run through the fluidic oscillators. The fluidic oscillator arrays were manufactured in two halves using direct metal laser sintering, DMLS, out of stainless steel which allowed for high accuracy of the internal flow passages. Figure $4 \mathrm{~b}$ shows the two oscillator halves prior to brazing with the flat internal brazing surfaces exposed. The two halves brazed together to form a single fluidic oscillator injector array and integrated into the combustor is shown in Figure 4a. The fluidic oscillator manifolds were fed by three inlets and provided pressure and temperature measurements through a fourth port. The fluidic oscillators were placed one inch downstream of the dump plane although a spacer plate, shown in Figure 4a, will allow them to be placed at 1.5 inches downstream of the dump plane while keeping the overall chamber length the same.

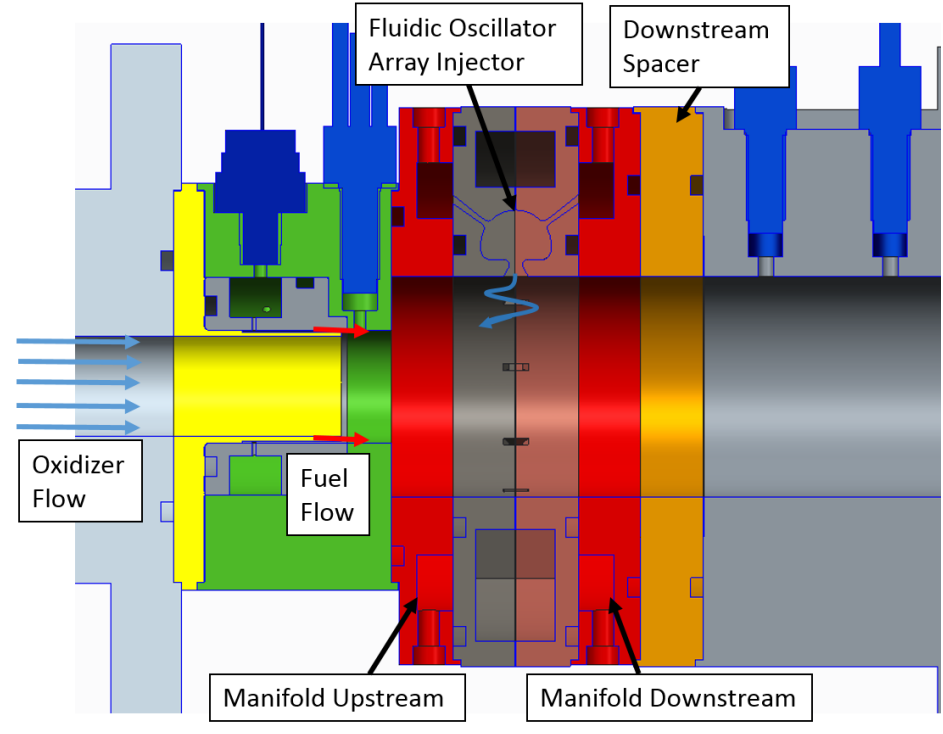

(a) The CVRC injection recess and fluidic injector assembly with oxidizer flow shown with blue arrows and fuel flow shown with red arrows.

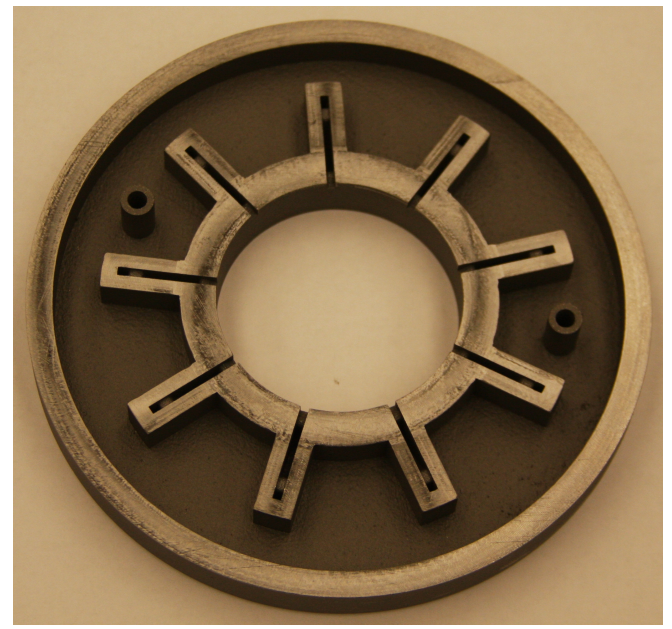

(b) One half of the fluidic injector 3-D printed hardware prior to brazing the two halves together

Figure 4. A close up of the fuel injector and fluidic injector shows the flow passages and high frequency pressure measurement locations. 
Flow characteristics for each design were confirmed through both water flow visual testing and high frequency microphone measurements with nitrogen gas to determine oscillation frequencies. The microphone data was gathered at $20 \mathrm{kHz}$ for 10 seconds from a PCB Piezotronics microphone, model 378B02, through a National Instruments dynamic signal acquisition board, PCI-4472. The microphone results shown in Figure 5 show only a slight variation in the frequency of each of the nine individual oscillators and also illustrates the differences in the oscillating and steady jet designs. The steady design exhibited only low frequency jet noise while the oscillating design showed a distinct jet oscillation frequency that increased with increasing pressure ratio. This trend matches microphone data from prior fluidic oscillator designs and testing. ${ }^{32}$

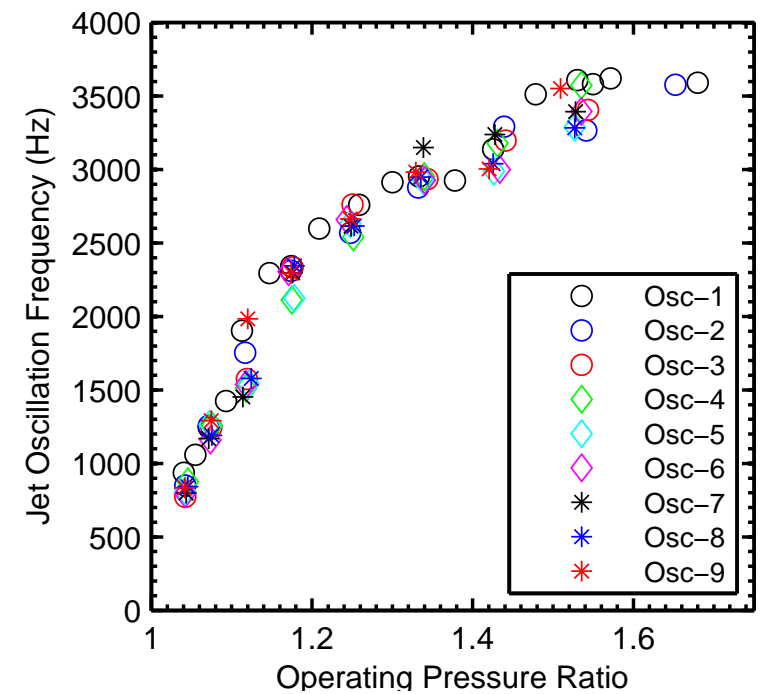

(a) Comparison of Individual Fluidic Oscillators

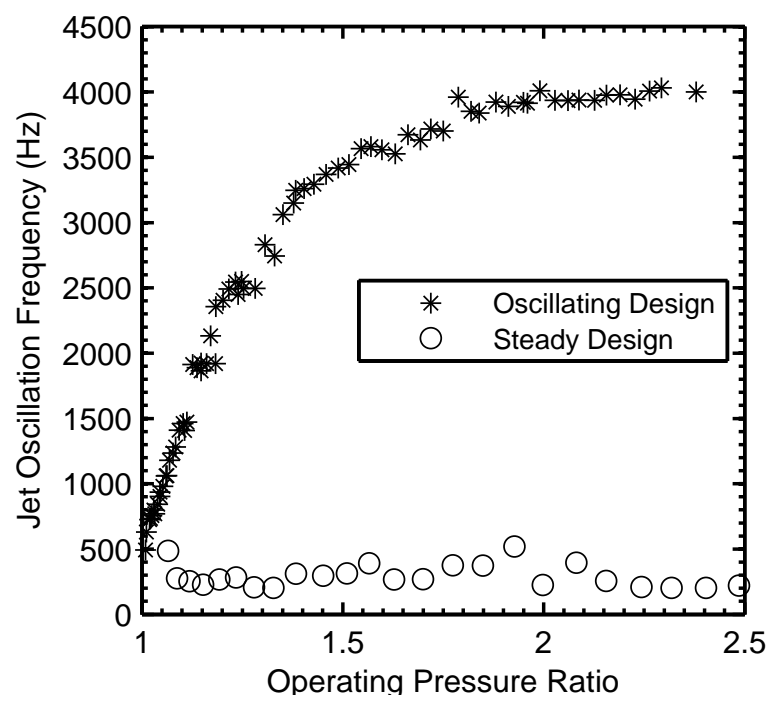

(b) Comparison of Oscillating and Steady Designs

Figure 5. Microphone data for the fluidic injectors shows a close coupling between the nine individual oscillators in the array and the constant low frequency jet noise resulting from the steady jet design compared to the oscillating jet design.

The fluidic oscillator injector supply line was directly connected to the main oxidizer manifold such that the fluidic oscillators were running when the main oxidizer valve was open. Due to the inability to turn the fluidic injectors off in this setup, the results are compared against identical flow rate conditions with the baseline CVRC chamber. The baseline chamber includes a solid chamber wall instead of the fluidic oscillator secondary injector with all of the oxidizer flowing through the oxidizer post. ${ }^{36-39}$ This allowed for a comparison of not only the steady vs oscillating jet, but also the effect of secondary oxidizer injection on the overall combustion stability. Table 1 shows the operating conditions for fluidic injector and baseline chamber tests. The addition of the fluidic injector oxidizer line resulted in a slight increase in flow area due to the fluidic injector sonic venturi, used to control the mass flow rate, and an increase in manifold volume behind the choke points, both of which contributed to the decrease in the oxidizer manifold pressure. Despite the lower oxidizer manifold pressure, the oxidizer post remained choked throughout the test.

Table 1. Secondary Oxidizer Injection Test Cases

\begin{tabular}{rrr} 
Parameter & Fluidic Injector Tests & Baseline Chamber Tests \\
\hline Fuel Mass Flow Rate, lb/s & 0.06 & 0.06 \\
Main Oxidizer Mass Flow Rate, lb/s & 0.6 & 0.7 \\
Fluidic Injector Mass Flow Rate, lb/s & 0.1 & N/A \\
Combustor O/F & 11.7 & 11.7 \\
Mean Chamber Pressure, psia & 215 & 215 \\
Oxidizer Manifold Pressure, psia & 530 & 610 \\
Fuel Manifold Pressure, psia & 470 & 470 \\
Fluidic Injector Manifold Pressure, psia & 270 & N/A
\end{tabular}




\section{Computational Model Development}

The computational platform for this analysis was the Loci/CHEM version 3.3 density based finite-volume solver under the Loci framework. ${ }^{42-45}$ The solution incorporated a hybrid Reynolds-averaged Navier-Stokes and large eddy simulation, RANS/LES, turbulence model ${ }^{46}$ with Menter's two equation Shear Stress Transport, SST, model ${ }^{47}$ using the Wilcox compressibility correction. ${ }^{48}$ The solver uses a second order solution in both space and time with an implicit three point backward time integration scheme. ${ }^{49}$ The portable, extensible toolkit for scientific computation, PETSc, solver was used for its robustness and stability. ${ }^{50-52}$ A time step of 1e-6 seconds proved sufficient based on a time step independence analysis of the results.

Due to computational cost limitations with the full three-dimensional combustor model, a one-step global methane/air chemistry model was used. The global one-step methane reaction shown in Equation 1, uses an Arrhenius reaction rate with modified concentration exponents to ensure robustness while still maintaining accuracy when compared to experimental data. The Arrhenius reaction rate is shown in Equation 2 where $\mathrm{T}$ is the temperature, $\mathrm{R}$ is the universal gas constant, $E_{a}$ is the activation energy, $\mathrm{A}$ is the pre-exponential factor, and a and b are concentration exponents. These reaction rate parameters and exponents, shown in Table 2, were calibrated to match atmospheric laminar flame speed over a range of equivalence ratios. ${ }^{53}$ The chemistry model includes five species consisting of Nitrogen, Oxygen, Water, Carbon Dioxide, and Methane although Nitrogen was considered inert during the combustion process.

$$
\begin{gathered}
\mathrm{CH}_{4}+2 \mathrm{O}_{2} \rightarrow 2 \mathrm{H}_{2} \mathrm{O}+\mathrm{CO}_{2} \\
k=A T^{n} \exp \left(-E_{a} / R T\right)\left[\mathrm{CH}_{4}\right]^{a}\left[\mathrm{O}_{2}\right]^{b}
\end{gathered}
$$

Table 2. Global One-Step Methane/Air Arrhenius Reaction Rate Parameters ${ }^{53}$

\begin{tabular}{rrr} 
Parameter & Value & Units \\
\hline $\mathrm{A}$ & $6.70 \times 10^{12}$ & $\mathrm{~cm}^{3} / \mathrm{gmol}-\mathrm{s}$ \\
$E_{a}$ & 48.4 & $\mathrm{cal} / \mathrm{gmol}-\mathrm{K}$ \\
$\mathrm{a}$ & 0.2 & N/A \\
$\mathrm{b}$ & 1.3 & N/A \\
$\mathrm{n}$ & 0 & N/A
\end{tabular}

The computational models were designed to match the 5.5 in oxidizer post length test case with decomposed hydrogen peroxide as the fluidic oscillator injector array working fluid. Both the steady and unsteady injector designs were considered. The 5.5 in oxidizer post length was selected because of the high baseline instability and the substantial amount of suppression observed with the oscillating fluidic injector array. The computational model consisted of a full 3-D model of the combustor with all nine oscillators and the oxidizer manifold as shown in Figure 6. The fuel manifold was not modeled due to the high computational cost associated with the 36 injection orifices. Previous CVRC computational studies have also omitted the fuel manifold feature with little impact to the results. ${ }^{39,54-56}$ In addition, the fluidic injector manifolds were neglected due to their high computational cost. It was thought that the small oscillator inlet passages (0.043in) would prevent any substantial backflow generated by the combustion instability pressure pulse. The oxidizer choke plate was simplified to axisymmetric for the computations by omitting the support structure. While the axisymmetric oxidizer post assumption causes a roughly $10 \%$ increase in flow area, the region remains choked with the only noticeable difference resulting in a lower oxidizer manifold pressure. As with neglecting the fuel manifold, previous computational studies have seen little impact from the axisymmetric assumption of the oxidizer choke plate. ${ }^{39,54-56}$ 


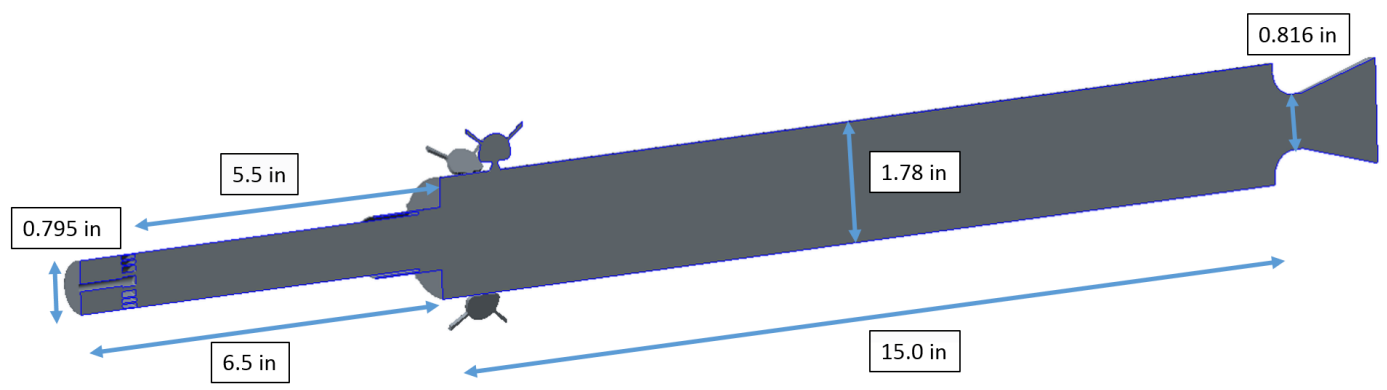

(a) Oscillating Jet Design Domain

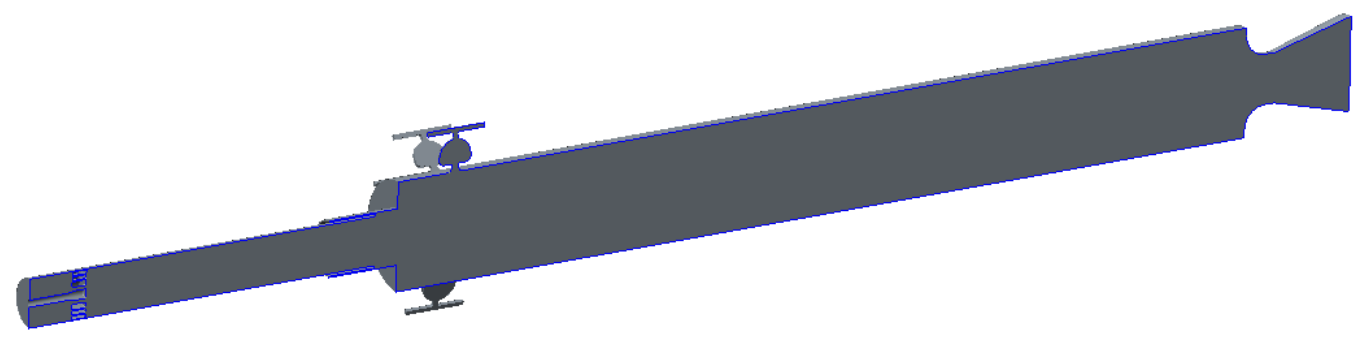

(b) Steady Jet Design Domain

Figure 6. Two computational domains consist of the 5.5 in oxidizer post length with the choke plate. The only difference is the design of the fluidic oscillators mounted around the dump plane.

The grid generation used an unstructured tetrahedral surface mesh generated using ANSA ${ }^{\mathrm{TM}}$ version 13.2.3. ${ }^{57}$ The volume mesh and hexahedral boundary layer were generated based on the surface mesh using AFLR3 version 12.29.61, Advancing-Front/Local-Reconnection, unstructured grid generator. ${ }^{58,59}$ Both the steady and oscillating fluidic injector grids contained close to 100 million elements with an overall "good" quality mesh as determined by the Loci/CHEM mesh inspection tool.

\section{Experimental Results}

The two baseline chamber tests along with the oscillating fluidic injector design were run with the oxidizer post translating from 7.5in to 3.5in for a total test duration of 3.5 seconds. Two baseline chamber tests were run to test the repeat-ability of the CVRC combustion response at an O/F of 11.7. The baseline cases showed almost identical frequencies and pressure oscillation magnitudes thus demonstrating consistent self-excited combustion instabilities over the range of oxidizer post lengths.

The steady injector design test series consisted of three individual one second tests at the discrete post lengths of 7.5, 5.5, and 3.5 inches. The translating oxidizer post tests were compared to the discrete tests by sampling 0.3 seconds of data corresponding to the desired post length as described in Table 3. Because of the test timing sequence, the 5.5 in ox-post length is the only translating length without 0.3 seconds of data. To account for this, the 0.3 second data band was centered at the 5.5in ox-post length thus including data from the $5.65 \mathrm{in}$ to $5.45 \mathrm{in}$ translation. The 0.3 seconds of data was block averaged with seven blocks to give a frequency resolution of $23 \mathrm{~Hz}$. Additionally the mean peak to peak pressure oscillations were calculated by averaging the peak of each pressure oscillation during the 0.3 seconds analyzed for each oxidizer post length. A summary of the combustion instability 1-L mode frequency and the chamber pressure oscillations observed during each test configuration is shown in Table 4. The results of the different injector tests compared very well in terms of the instability frequencies at each oxidizer post length.

Table 3. Data Slices Analyzed for Each Ox Post Length for Translating Test Data

\begin{tabular}{rr} 
Post Length & Translating Test Time Band \\
\hline 7.5 in & $10.7-11.0 \mathrm{~s}$ \\
$5.5 \mathrm{in}$ & $12.0-12.3 \mathrm{~s}$ \\
$3.5 \mathrm{in}$ & $13.1-13.4 \mathrm{~s}$
\end{tabular}


Table 4. First Longitudinal Mode and Chamber Pressure Fluctuations for Each Peroxide Test Case

\begin{tabular}{rrrrr} 
Ox Post Length & Oscillating Design & Steady Design & Baseline 1 & Baseline 2 \\
\hline 7.5 inches & $\begin{array}{r}1310 \mathrm{~Hz} \\
+10 /-9 \mathrm{psi}\end{array}$ & $\begin{array}{r}1210 \mathrm{~Hz} \\
+9 /-9 \mathrm{psi}\end{array}$ & $\begin{array}{r}1280 \mathrm{~Hz} \\
+43 /-35 \mathrm{psi}\end{array}$ & $\begin{array}{r}1280 \mathrm{~Hz} \\
+47 /-36 \mathrm{psi}\end{array}$ \\
\hline \multirow{2}{*}{5.5 inches } & $1370 \mathrm{~Hz}$ & $1390 \mathrm{~Hz}$ & $1350 \mathrm{~Hz}$ & $1360 \mathrm{~Hz}$ \\
& $+24 /-17 \mathrm{psi}$ & $+69 /-38 \mathrm{psi}$ & $+88 /-38 \mathrm{psi}$ & $+87 /-38 \mathrm{psi}$ \\
\hline 3.5 inches & $1510 \mathrm{~Hz}$ & $1490 \mathrm{~Hz}$ & $1470 \mathrm{~Hz}$ & $1530 \mathrm{~Hz}$ \\
& $+13 /-11 \mathrm{psi}$ & $+17 /-13 \mathrm{psi}$ & $+13 /-11 \mathrm{psi}$ & $+13 /-11 \mathrm{psi}$
\end{tabular}

The estimated jet oscillation frequency for the oscillating fluidic injector design was roughly $3500 \mathrm{~Hz}$. This estimate is based off of the frequency vs pressure ratio curves experimentally measured using nitrogen gas with a microphone and shown in Figure 5b. The equivalent nitrogen gas frequency for the experimental oscillators, 2600 $\mathrm{Hz}$, is then scaled by a factor of 1.36 to account for the frequency of decomposed hydrogen peroxide. This scale factor was determined using 2-D CFD analysis as described by Meier et. al. with decomposed hydrogen peroxide frequencies compared to the equivalent room temperature nitrogen gas oscillation frequency. ${ }^{32}$ The decomposed hydrogen peroxide was simulated using a mixture of $57.65 \% \mathrm{H}_{2} \mathrm{O}$ and $42.35 \% \mathrm{O}_{2}$ by mass at the experimentally measured oscillator manifold temperature of $400^{\circ} \mathrm{F}$. The lower density and higher speed of sound give the decomposed peroxide a frequency increase over the room temperature nitrogen gas. The low frequency chamber pressure transducer and the fluidic injector manifold pressure measurements were used to determine the operating pressure ratio for this estimate.

\section{IV.A. $\quad 7.5$ inch Oxidizer Post Length}

The 7.5in oxidizer post length saw almost a 60 psi reduction in peak to peak pressure oscillations with both the oscillating and steady jet injector as shown in Figure 7. The 7.5in post length was moderately unstable with the baseline chamber resulting in mean chamber pressure oscillations of 80 psi. The secondary oscillating and steady jet injection of decomposed hydrogen peroxide was able to reduce these chamber pressure oscillations to 8 psi. Since both the steady and oscillating jet resulted in similar performance, the instability reduction is a result of the secondary oxidizer injection and not the oscillating action of the fluidic oscillators. 


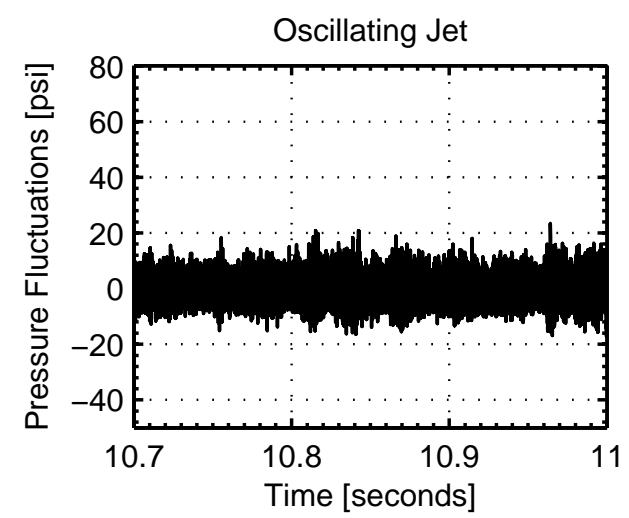

(a) Oscillating Jet Injection

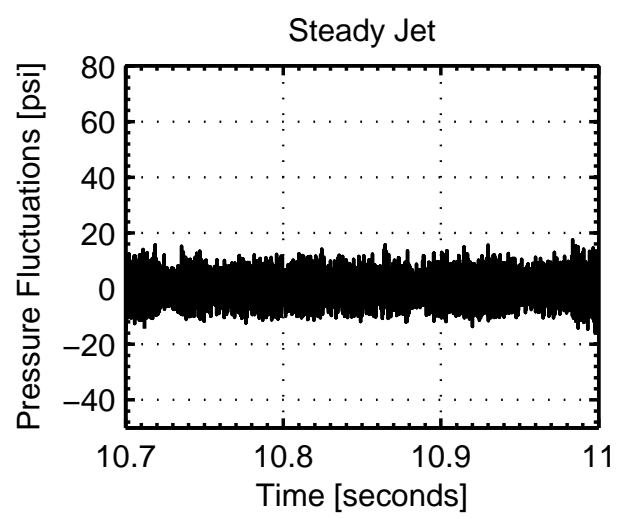

(b) Steady Jet Injection

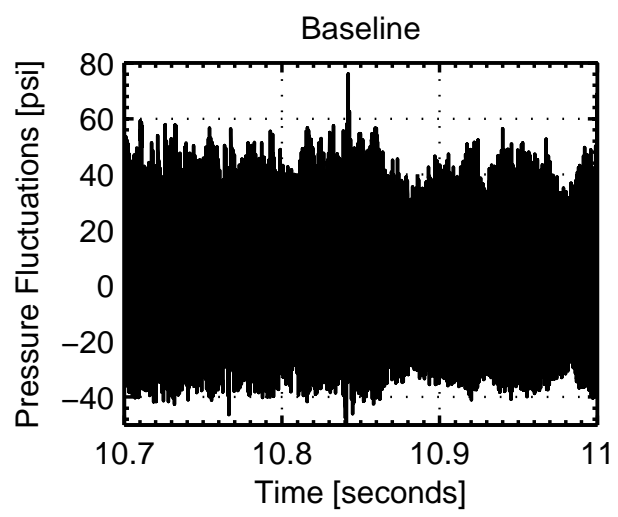

(c) Baseline Chamber Test

Figure 7. Chamber pressure fluctuation data for the 7.5in ox post length shows the large reduction with the fluidic oxidizer injection.

Both fluidic injector designs resulted in a two order of magnitude reduction in the 1-L combustion instability mode as shown in Figure 8. The steady jet showed a larger suppression of the 1-L mode over the oscillating jet, however, the steady jet saw much less reduction in the 2-L mode. The steady jet 2-L mode shows a higher frequency than the baseline chamber design suggesting a higher chamber temperature possibly resulting from increased mixing due to the secondary oxidizer injection. While the oscillating jet fluidic injector design had a larger 1-L magnitude than the steady jet, it was able to further suppress the 2-L mode by two orders of magnitude when compared to the steady jet. Despite the differences in dominant instability modes, both the steady jet and oscillating jet injectors saw almost identical peak to peak pressure oscillations as shown in Table 4. 


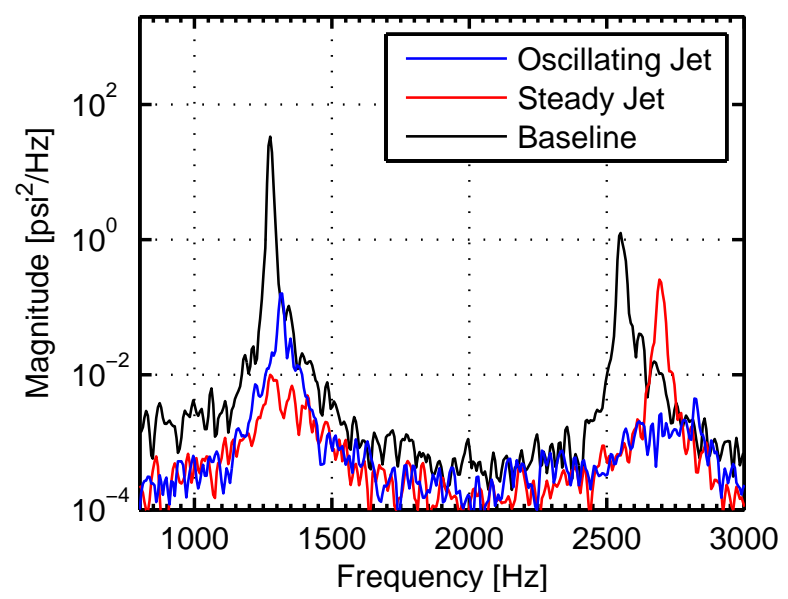

Figure 8. Power spectral density data for the chamber at the 7.5in ox post length illustrates the large amplitude reduction for both fluidic injector designs. The frequency resolution is $23 \mathrm{~Hz}$.

\section{IV.B. 5.5 inch Oxidizer Post Length}

The 5.5in oxidizer post length proved to be the most unstable post length for the baseline chamber design as evident by the 126 psi peak to peak chamber pressure oscillations shown in Figure 9. The steady jet fluidic injector design showed only a moderate $15 \%$ psi drop in the peak to peak pressure oscillations as evident by Table 4 . Despite this moderate reduction from the steady jet injection, the combustor remained unstable as evident by the high amplitude pressure oscillations shown in Figure 9b. The oscillating jet design showed a 67\% reduction in combustion chamber pressure oscillations. This 52\% improvement over the steady jet design shows the benefits of the passively modulated fluidic oscillator unsteady injection over steady secondary injection. The unsteady nature of the oscillating injector design was able to further decouple the heat release from the pressure oscillations resulting in more stable combustor operation when compared to the baseline chamber results. 


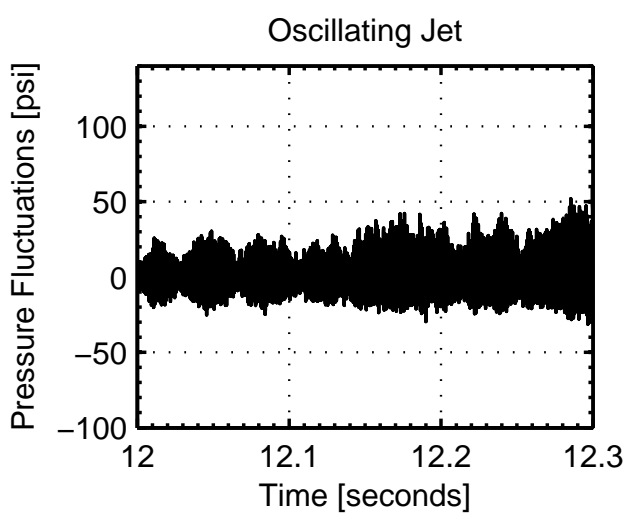

(a) Oscillating Jet Injection

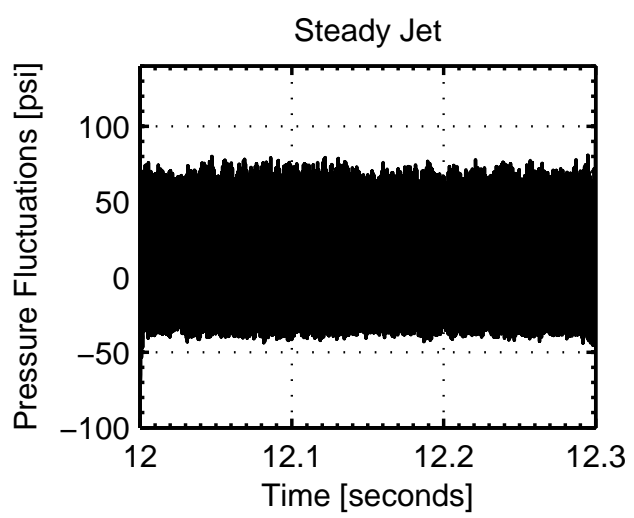

(b) Steady Jet Injection

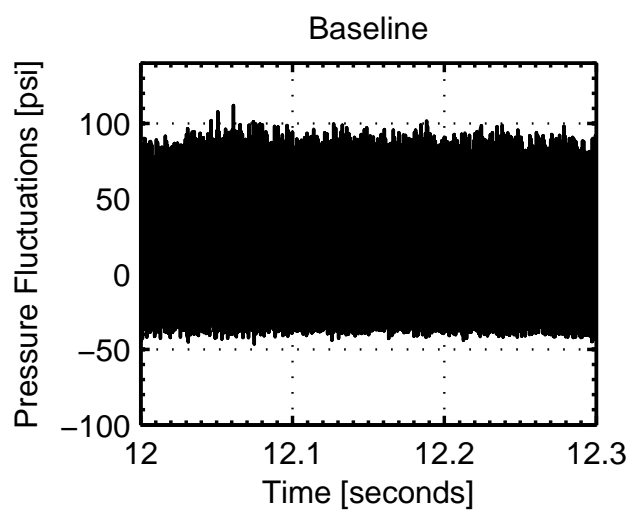

(c) Baseline Chamber Test

Figure 9. Chamber pressure fluctuation data for the 5.5in ox post length shows a large reduction for the oscillation injector while the steady injector remains very unstable.

The power spectral density graph illustrated in Figure 10 shows a slight amplification for the first two modes for the steady jet injection over the baseline case. The oscillating jet design shows almost an order of magnitude reduction in the instability. In addition, Figure 11 shows that the oscillating jet design disrupts the formation of higher order modes associated with the unstable cases. This shows that the oscillating jet action is not just transferring energy between instability modes, but instead disrupting the transfer of energy into the pressure oscillations.

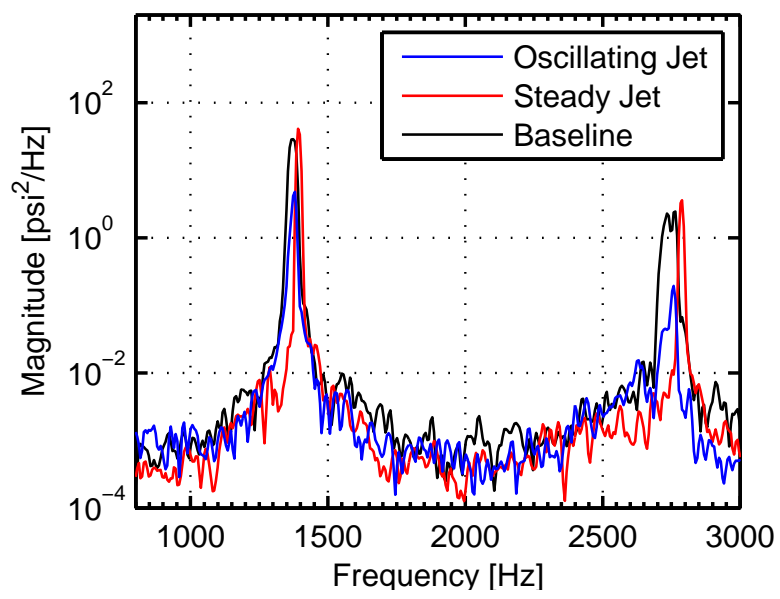

Figure 10. Power spectral density data for the chamber at the 5.5in ox post length illustrates the large amplitude reduction for both fluidic injector designs. The frequency resolution is $23 \mathrm{~Hz}$. 


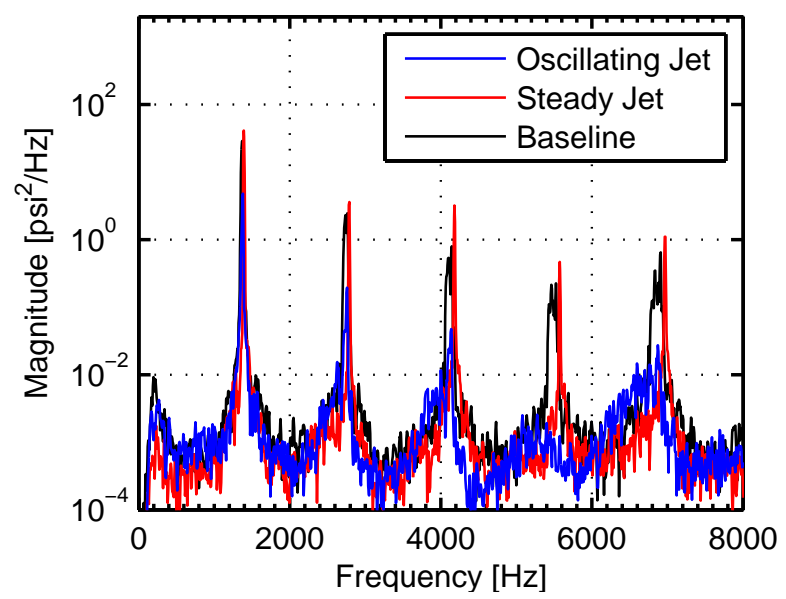

Figure 11. Power spectral density data for the chamber at the 5.5in ox post length illustrates the lack of higher order modes for the oscillating jet injection design. The frequency resolution is $23 \mathrm{~Hz}$.

\section{IV.C. 3.5 inch Oxidizer Post Length}

The 3.5in oxidizer post length proved to be moderately stable for all three chamber designs with little difference between them as illustrated in Figure 12. The steady jet injection design exhibited slightly higher pressure oscillations than the baseline design and oscillating jet injector as shown in Table 4. Despite the passively modulated oxidizer injection through the oscillating fluidic injectors, no stability improvement was seen in either the pressure oscillations or the power spectral density graph as shown in Figures 12 and 13. This suggests that the combustion response to the pressure oscillations at this oxidizer post length is unaffected by the modulated secondary oxidizer injection. 


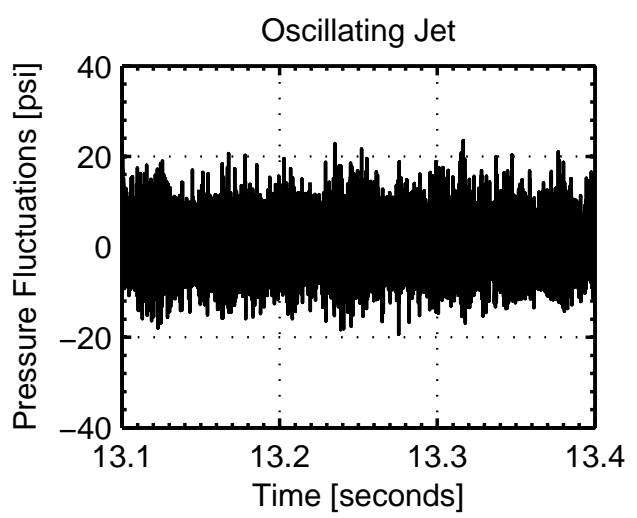

(a) Oscillating Jet Injection

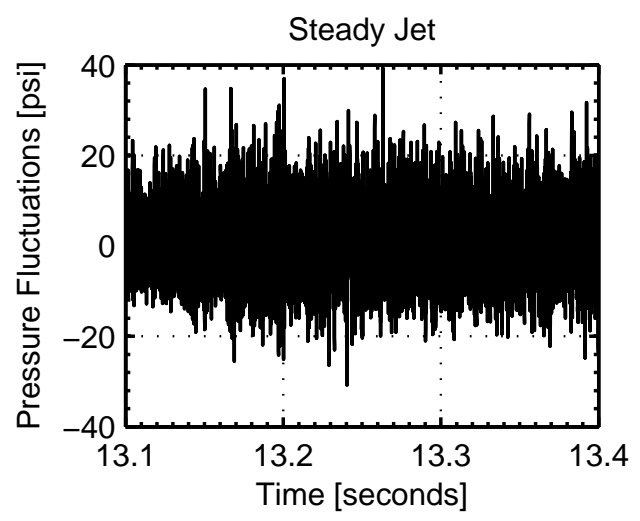

(b) Steady Jet Injection

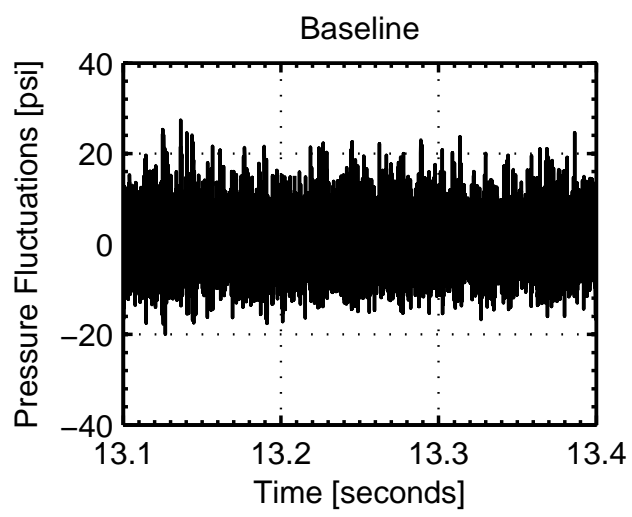

(c) Baseline Chamber Test

Figure 12. Chamber pressure fluctuation data for the 3.5in ox post length shows almost no difference between the three different injector configurations.

The power spectral density graph illustrated in Figure 13, shows almost no difference in the first and second longitudinal modes for the three chamber designs. The steady jet injection shows a slight amplification of the 3-L mode by an order of magnitude. The overall frequencies are very similar between the three injector designs suggesting no major differences in mixing and combustion efficiency.

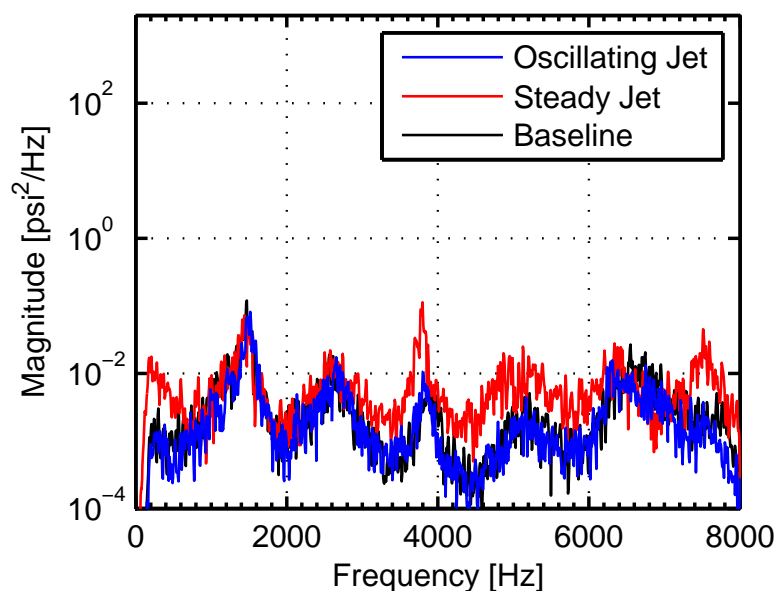

Figure 13. Power spectral density data for the chamber at the 3.5in ox post length illustrates the large amplitude reduction for both fluidic injector designs. The frequency resolution is $23 \mathrm{~Hz}$. 


\section{IV.D. Translating Oxidizer Post Tests}

Translating oxidizer post tests were run with both the baseline chamber and the oscillating fluidic injector to study the combustion response over a range of oxidizer post lengths from $7.5 \mathrm{in}$ to $3.5 \mathrm{in}$. The aft chamber pressure fluctuations at the 14.5in pressure location, shown in Figure 14, reveal the combustion instability response to the changing oxidizer post length with the baseline chamber and oscillating injector configurations. The oscillating fluidic injector was able to suppress the combustion instabilities in the 7.5in to 5.25in oxidizer post range. At an oxidizer post length of 5 inches, the pressure oscillations nearly matched the baseline chamber instability.

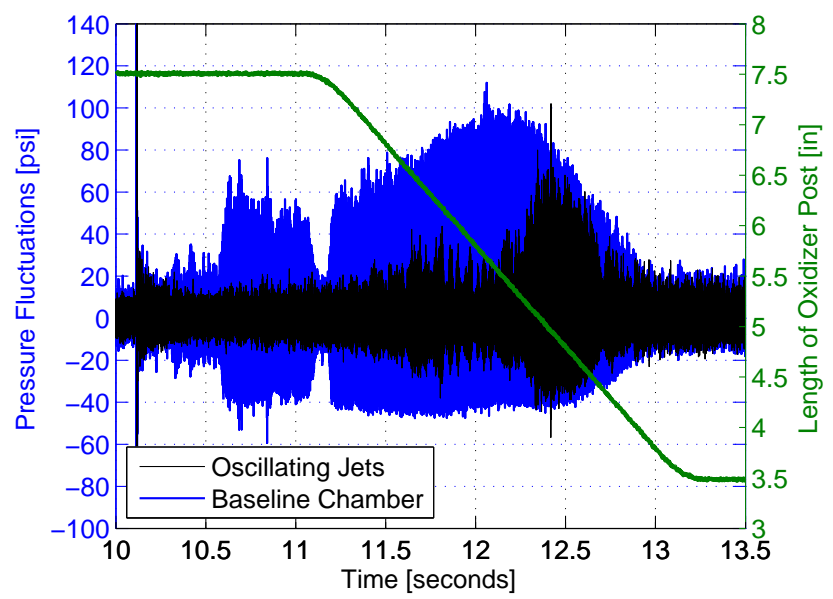

Figure 14. Translating test pressure oscillations measured at the 14.5in chamber location show a significant reduction over most of the oxidizer post lengths with the oscillating jet injection.

The spectrograms shown in Figure 15 reveal the reduction in magnitude at all of the combustion instability modes with the oscillating jet injector compared to the baseline chamber. Looking at Figure 15a, with the oscillating injector, the first mode of $\sim 1350 \mathrm{~Hz}$ is present throughout the duration of the hot fire test, however, the onset of the second and third modes are greatly delayed and the fourth mode is almost completely absent during the test.

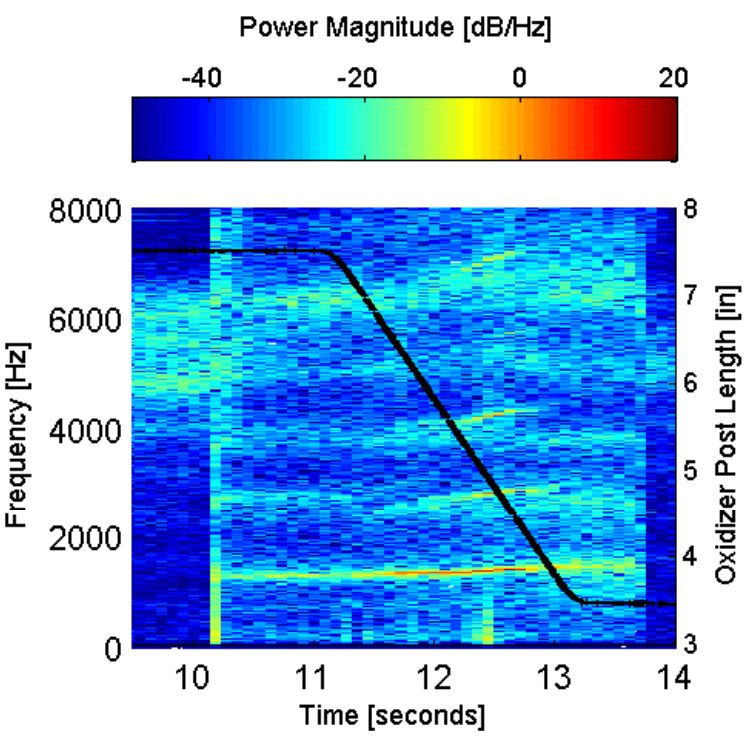

(a) Oscillating Jet Injection

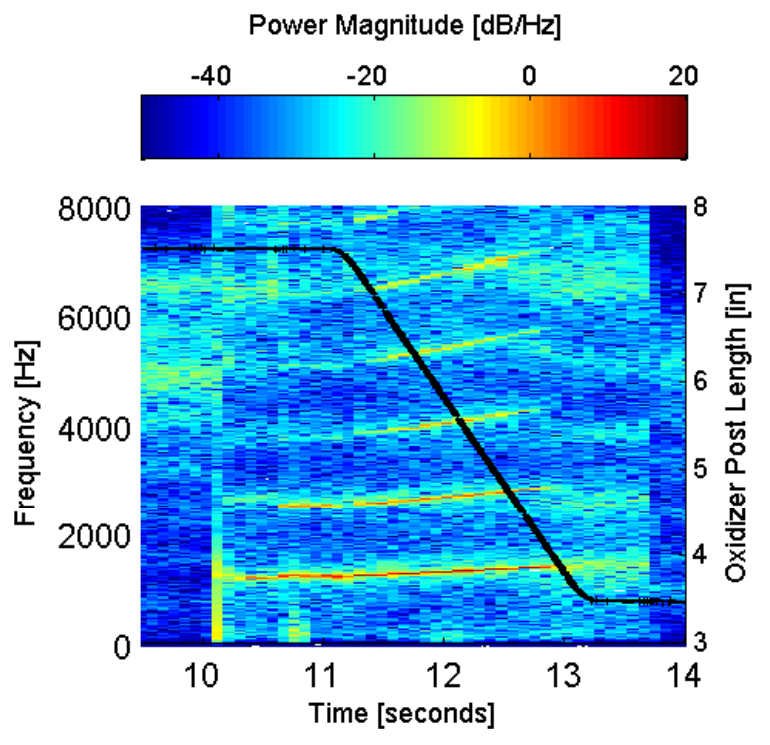

(b) Baseline Chamber Test 1

Figure 15. Spectrograms of the 14.5in chamber pressure measurement location reveal a substantial reduction in all the instability modes with the oscillating jet injection. The spectrogram frequency resolution is $10 \mathrm{~Hz}$. 


\section{Computational Results}

\section{V.A. Steady Jet Injection Model}

The steady jet injection CFD model showed good agreement with the experimental results as shown in Table 5 with a total of $28 \mathrm{~ms}$ of limit cycle instability data obtained. The slightly higher frequencies in the computational data stem from the simplified chemistry model resulting in a higher overall chamber temperature and thus higher speed of sound within the combustor. Additionally, local time stepping present in the implicit CFD solver could allow the pressure pulse to travel slightly faster than the speed of sound and artificially increase the frequency. Also shown in Table 5 are the results from a previous CVRC simulation with the baseline combustor. As discussed earlier, the baseline combustor has no secondary injection, but operates at the same $\mathrm{O} / \mathrm{F}$ ratio as the secondary oxidizer injection cases. The experimental results for the baseline chamber and steady jet injection instability 1-L frequency were similar as evident by Table 4, suggesting good agreement of the steady jet model with prior computational models performed with a different mesh and solver. ${ }^{39}$

Table 5. Comparison of Computational and Experimental Instability Frequencies

\begin{tabular}{rrrr} 
Instability Mode & Steady Jet Model & Experimental Data & Previous CVRC CFD ${ }^{39}$ \\
\hline 1-L Mode & $1550 \mathrm{~Hz}$ & $1392 \mathrm{~Hz}$ & $1570 \mathrm{~Hz}$ \\
2-L Mode & $3080 \mathrm{~Hz}$ & $2789 \mathrm{~Hz}$ & $3110 \mathrm{~Hz}$ \\
3-L Mode & $4640 \mathrm{~Hz}$ & $4181 \mathrm{~Hz}$ & $4690 \mathrm{~Hz}$
\end{tabular}

The steady jet combustion instability cycle was broken into six stages as shown in Figure 16. These stages are characterized by pressure events in the injection recess and illustrate the unsteadiness in the combustion process. Figure 16 illustrates one complete instability cycle with limit cycle amplitudes with the six stages labeled by the red dots.

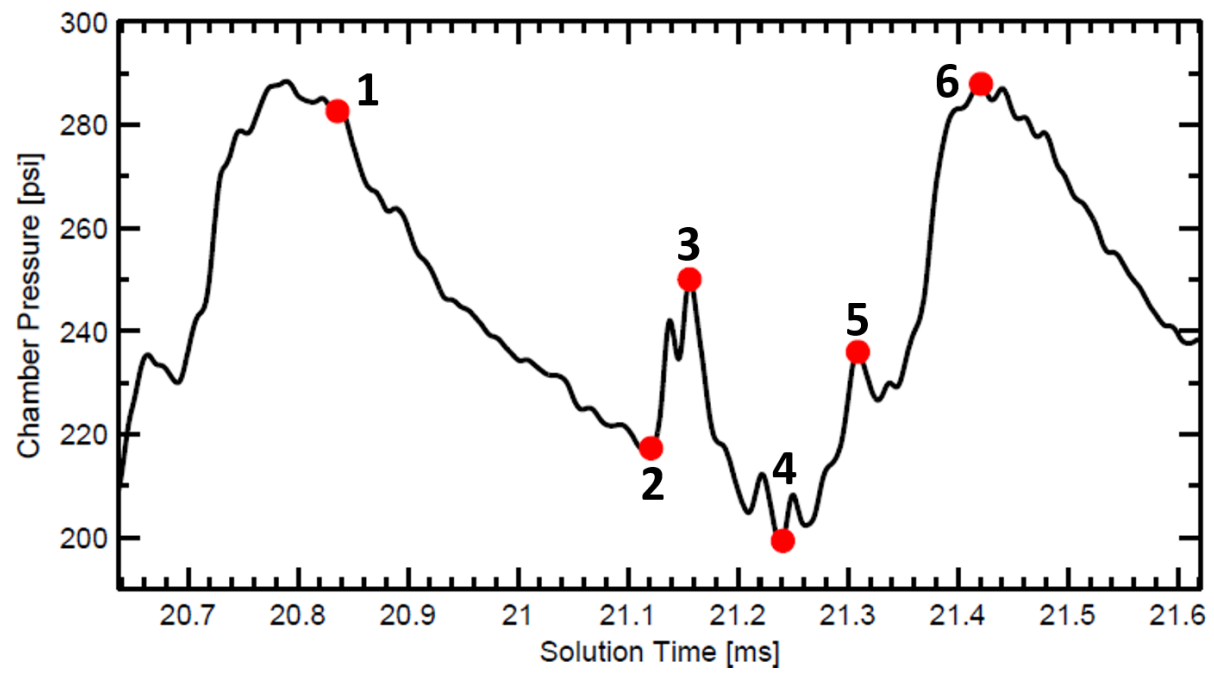

Figure 16. One instability pressure oscillation cycle was broken down into six stages of events using the injection recess pressure measurement.

Figure 17 illustrates the movement of the pressure pulse through the computational domain at each stage of the cycle. The first stage shows the pressure pulse traveling upstream through the oxidizer post and reflecting off of the dump plane. At stage two, the chamber pressure pulse has reached the aft end while the oxidizer post pressure pulse has reached the head end. The difference in pulse speeds is a result of the large temperature difference between the oxidizer flow and the combustion gases producing a difference in the speed of sound. The third stage sees the oxidizer post pulse returning to the injection region an expanding into the chamber while the chamber pulse is only halfway back down the chamber. Stage four sees the movement of a fuel rich vortex into the re-circulation region as a result of the oxidizer post pressure pulse exiting into the chamber. Stage five is when the returning chamber pressure pulse reaches the fluidic injector and begins suppressing the fluidic injector oxidizer flow. At stage six, the pressure pulse has reached the dump plane and the cycle resumes. 


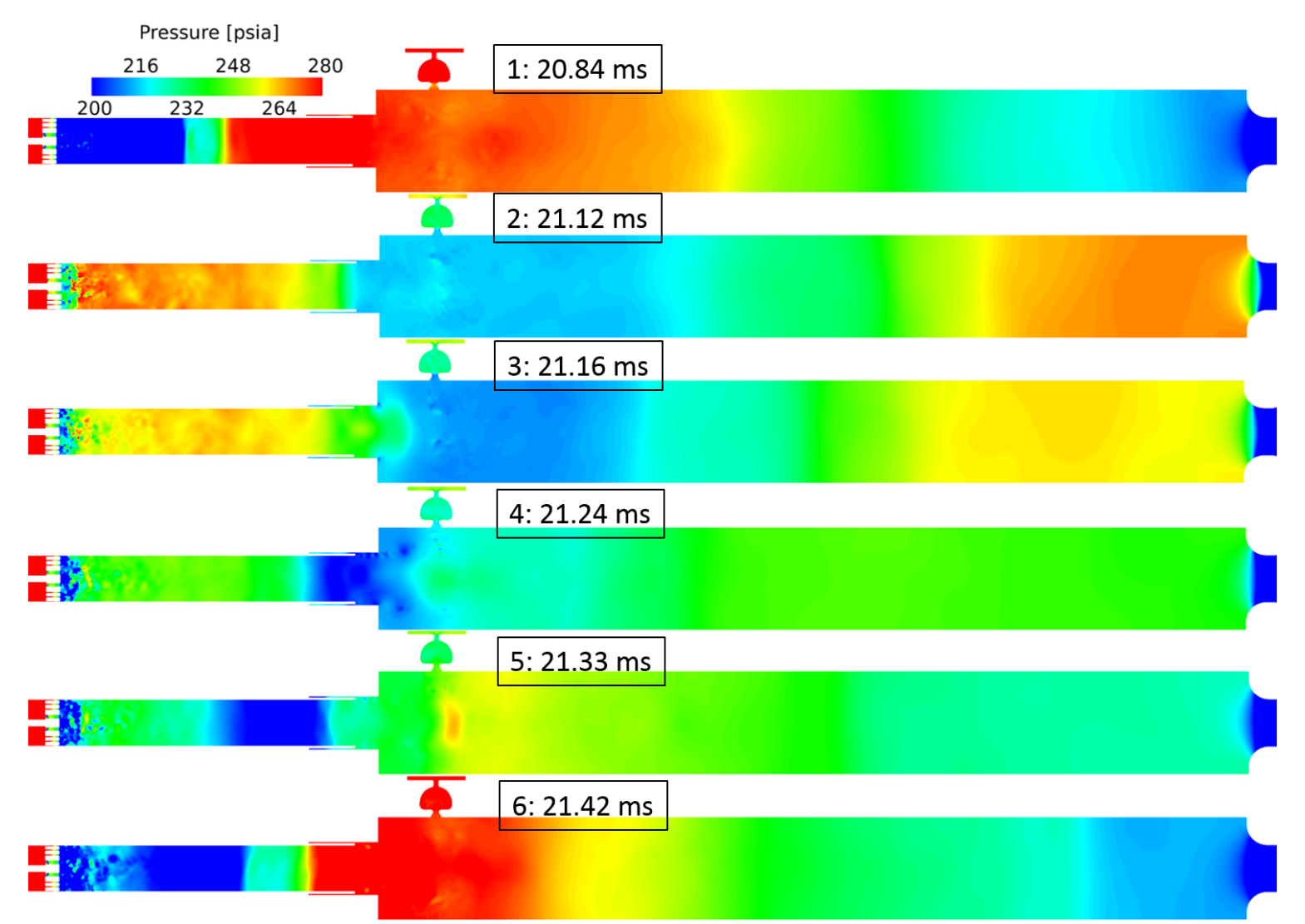

Figure 17. The unsteady pressure oscillations throughout the domain illustrate the movement of the high pressure pulse with the steady fluidic injectors.

The methane concentration in Figure 18a and the velocity magnitude in Figure 18b, both with contours of static pressure, illustrate the fuel injection behavior and the performance of the steady jet within the combustor. The cycle begins with the pressure pulse leaving the injection region. Low concentrations of methane fuel result from the rapid mixing and combustion associated with the arrival of the pressure pulse. It can also be seen that the fuel flow and fluidic oscillator flow have temporarily ceased due to the pressure pulse translating into the injection region and fuel collar. With the pressure pulse moving away from the injection region, the second stage sees resumed propellant flow through both the fuel injector and fluidic oscillators. While there is little combustion during this time due to the recovery of the injectors from the pressure pulse, the combustion gases in the re-circulation zone remain hot enough to restart combustion. Stage three sees the pressure pulse from the oxidizer post return and expand into the chamber. The fourth stage shows the methane rich vortex moving into the re-circulation zone as a result of the oxidizer pressure pulse entering the chamber. At stage five, the methane rich vortex has reached the fluidic injector jets which have disrupted the vortex shape although the high methane concentration remains unburned. Also at this time, the chamber pressure pulse is beginning to alter the fluidic injector flow path and ultimately suppress the fluidic jet flow due to the backflow induced by the high pressure pulse. Stage six sees the rapid mixing of the methane concentrated regions with a temporary stall on the fluidic injector oxidizer flow leading back to stage one conditions. This operation shows a strong coupling of the fuel injector, steady fluidic injector, and combustion events with the chamber pressure pulse leading to the high amplitude instability. 


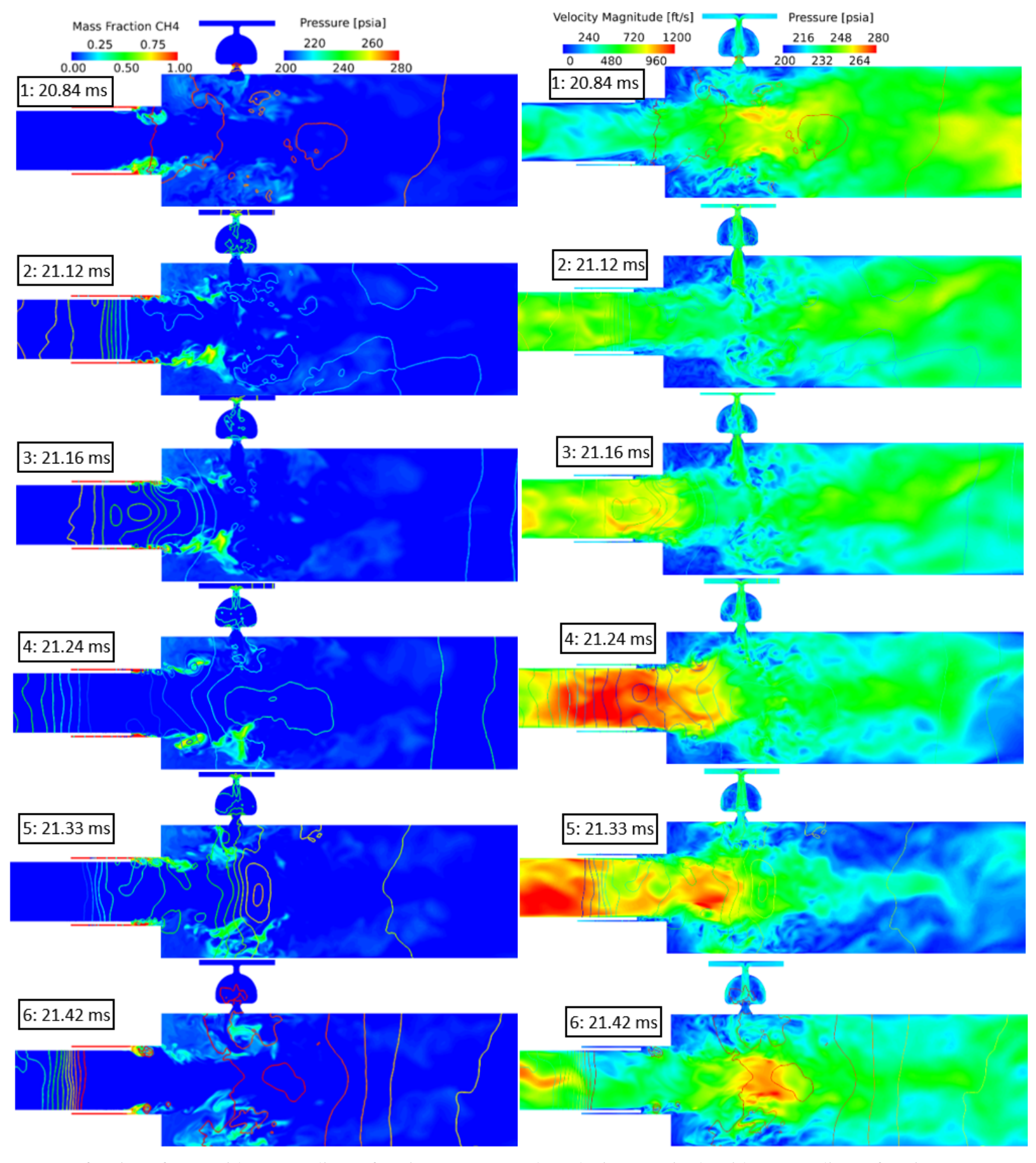

(a) Mass fraction of $\mathrm{CH}_{4}$ with contour lines of static pressure.

(b) Velocity magnitude with contour lines of static pressure.

Figure 18. The instability cycle can be characterized by rapid propellant mixing and burning upon arrival of the high pressure pulse to the injection region. Additionally, the steady jet oxidizer flow is shut off during the return of the high pressure pulse.

\section{V.B. Oscillating Jet Injection Model}

The oscillating jet injection case did not agree with the experimental results, possibly due to the simplified chemistry model not adequately capturing the periodic heat release resulting from the fluidic oscillator unsteady injection. Other factors such as mesh density, boundary conditions, fluidic oscillator frequency, and pressure pulse timing were all investigation with no change in the combustor instability behavior. ${ }^{60}$ Despite the lack of agreement with the experi- 
mental data, the velocity magnitude results shown in Figures 19 and 20 illustrate the effect of the unsteady injectors on the combustor flow field. Figure 19 illustrates a planar view of the combustor during the low pressure injector portion of stage four of the instability cycle. The oscillating jet is seen interacting with the main propellant flow from the coaxial injector. Figure 20 shows an axial view of the fluidic oscillator injection plane at the same low pressure point in the cycle. The jets penetrate the re-circulation zone creating additional shear-mixing surface area for the propellants.

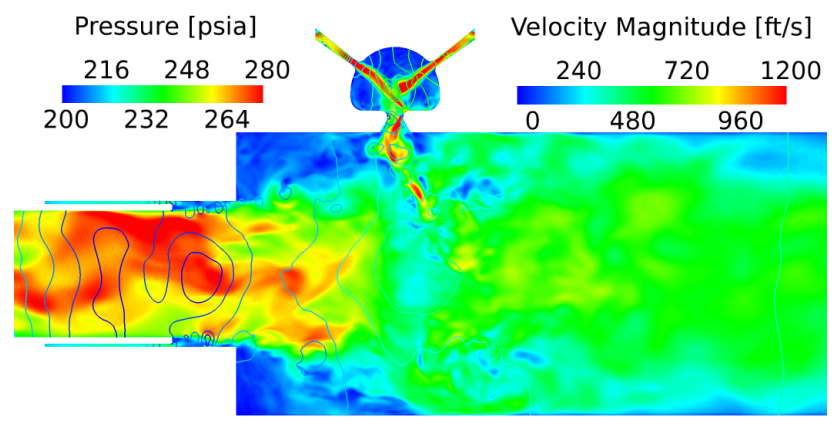

Figure 19. The velocity magnitude contour with iso lines of static pressure shows the unsteady nature of the oscillating jet design.

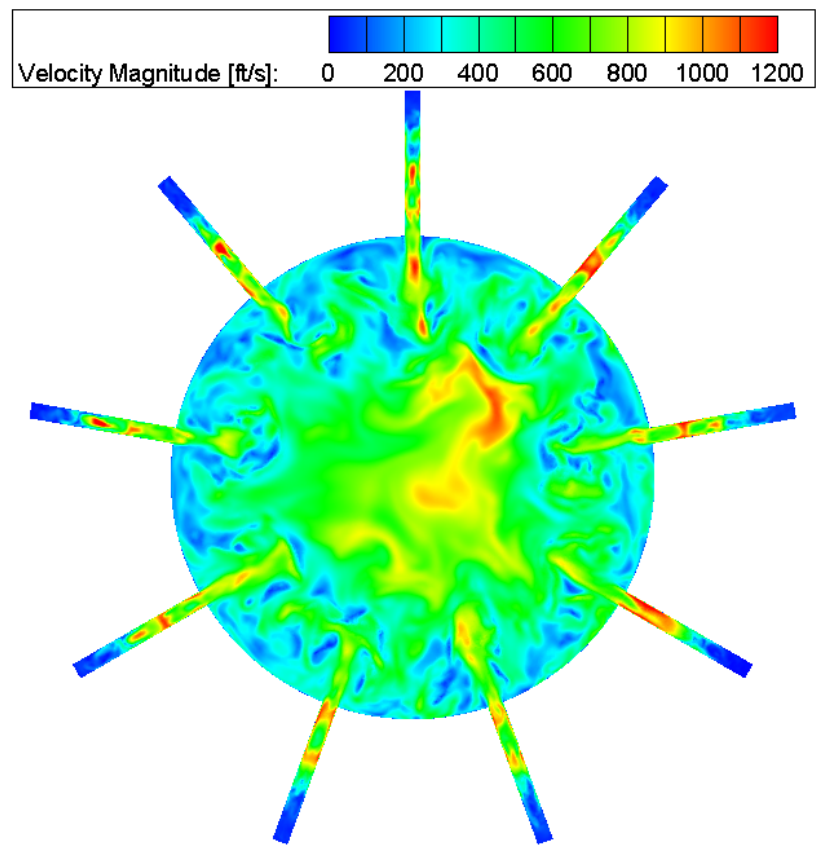

Figure 20. An axial view of the velocity magnitude shows the effect of the oscillating jet injection on the flow field.

\section{Conclusions}

The modulated secondary oxidizer injection created by the oscillating fluidic injector design proved successful in suppressing high amplitude acoustic instabilities by up to $67 \%$ at several oxidizer post lengths. The secondary oxidizer injection tests diverted $15 \%$ of the main oxidizer flow to the fluidic injectors. Both the steady and oscillating jets showed suppression at the moderately unstable 7.5 in oxidizer post length. The most unstable 5.5 in oxidizer post length saw a $67 \%$ reduction of the $1400 \mathrm{~Hz}$ combustion instability with the oscillating jets while only a slight reduction with the steady jet injection. This difference highlights the unsteady nature of the oscillating jet as more effective at decoupling the combustion response from the chamber pressure oscillations when compared to the equivalent steady jet injection. The relatively stable chamber conditions at the 3.5 in oxidizer post length saw the oscillating jets match the baseline chamber conditions and a slight increase in the chamber pressure oscillation magnitude with the steady jets. This suggests that the combustion response to the pressure oscillations at the 3.5in oxidizer post length is unaffected 
by the modulated secondary oxidizer injection.

Comparing the oscillating jet and baseline chamber translating oxidizer post tests shows combustion instability suppression for oxidizer post lengths greater than 5 inches. At oxidizer post lengths shorter than 5 inches, the oscillating jet chamber pressure oscillations nearly matched the baseline chamber results. At the shorter post lengths, the oscillating jet was unable to adequately disrupt the feedback mechanism between the heat release and pressure oscillations.

Computational fluid dynamic results showed a strong coupling of the steady jet injection to the pressure oscillations resulting in sustained unstable operation at the 5.5in oxidizer post length. The steady jet injection model agreed very closely with the experimental results and past CVRC CFD analysis without the secondary injection. While the oscillating jet case was unable to match the experimental results due to the simplified chemical kinetics in the model, the results show the interaction of the unsteady jet with the surrounding flow field. The oscillating jet injection allows for periodic mixing in the re-circulation zone as the jets penetrate well into the combustor. The CFD results indicate that the periodic combustion process is very dependent on the chemical kinetics as the simplified one step methane reaction model was unable to match the oscillating jet experimental results.

This work demonstrates the use of fluidic devices design to suppress combustion instability in open loop control. Fluidic devices have a high degree of reliability when compared to other propellant modulating devices such as fast actuating valves and speakers as fluidics require no moving parts or electrical power to operate. The advent of additive manufacturing allows for integration of the complex fluidic oscillator geometry into rocket injectors to provide combustion control.

\section{Acknowledgments}

The authors graciously acknowledge the Charles C. Chappelle Fellowship and the NASA Space Technology Research Fellowship for providing funding and support for this project. The authors would also like to thank W. Zach Hallum, Tristan L. Fuller, Michael J. Bedard, Swanand V. Sardeshmukh, Cheng Huang, and Matthew K. Wierman from Purdue University for their help in test operations and analysis model development. Additionally, the authors would like to thank Jeff West and Brian Richardson from the NASA Marshall Space Flight Center for their help throughout the computational fluid dynamics model development and analysis.

\section{References}

\footnotetext{
${ }^{1}$ Bennewitz, J. W. and Frederick, R. A. Overview of Combustion Instabilities in Liquid Rocket Engines - Coupling Mechanisms \& Control Techniques. 49th AIAA Joint Propulsion Conference, pages 1-24, June 2013.

${ }^{2}$ Schadow, K. C., Gutmark, E., and Parr, T. P. Study of Combustion Dynamics for Passive and Active Control. In Kuhl, A. L., Leyer, J. C., Borisov, A. A., Sirignano, W. A., and Seebass, A. R., editors, Dynamics of Gaseous Combustion, pages 365-388. American Institute of Aeronautics and Astronautics, Jan. 1993.

${ }^{3}$ Paschereit, C. O. and Gutmark, E. Passive Combustion Control for Enhanced Stability and Reduced Emissions in a Swirl-Stabilized Burner. 41st Aerospace Sciences Meeting and Exhibit, pages 1-12, Jan. 2003.

${ }^{4}$ Neumeier, Y., Nabi, A., Ben Zinn, T., and Lewis Jr., D. S. Investigation of the open loop performance of an active control system utilizing a fuel injector actuator. 32nd AIAA/ASME/SAE/ASEE Joint Propulsion Conference and Exhibit, pages 1-23, July 1996.

${ }^{5}$ Langhorne, P. J., Dowling, A. P., and Hooper, N. Practical active control system for combustion oscillations. Journal of Propulsion and, 6(3):324-333, May 1990.

${ }^{6}$ Mohanraj, R., Neumeier, Y., and Ben Zinn, T. Combustor Model for Simulation of Combustion Instabilities and Their Active Control. Journal of Propulsion and Power, 16(3):485-491, May 2000.

${ }^{7}$ Neumeier, Y., Nabi, A., Arbel, A., Vertzberger, M., and Ben Zinn, T. Open-Loop Performance of a Fast-Response, Actively Controlled Fuel Injector Actuator. Journal of Propulsion and Power, 13(6):705-713, Nov. 1997.

${ }^{8}$ Uhm, J. H. and Acharya, S. Control of combustion instability with a high-momentum air-jet. Combustion and Flame, 139(1-2):106-125, Oct. 2004

${ }^{9}$ Uhm, J. H. and Acharya, S. Low-bandwidth open-loop control of combustion instability. Combustion and Flame, 142(4):348-363, Sept. 2005.

${ }^{10} \mathrm{Uhm}, \mathrm{J}$. H. and Acharya, S. Role of low-bandwidth open-loop control of combustion instability using a high-momentum air jet-mechanistic details. Combustion and Flame, 147(1-2):22-31, Oct. 2006.

${ }^{11}$ Wachsman, A., Park, S., Sobhani, Z. C., Annaswamy, A. M., and Ghoniem, A. F. Simultaneous Combustion Instability and Emissions Control Using Air and Fuel Modulation. 42nd AIAA Aerospace Sciences Meeting and Exhibit, pages 1-10, Jan. 2004.

${ }^{12}$ Kurimoto, N., Suzuki, Y., and Kasagi, N. Active Control of Coaxial Jet Mixing and Combustion with Arrayed Micro Actuators. Experimental Heat Transfer, Fluid Mechanics and Thermodynamics, pages 511-516, Oct. 2001.

${ }^{13}$ Park, S., Ghosh, A., Diao, Q., and Yu, K. H. Optimizing Combustion Instability Suppression Using Secondary Fuel Injection. 47th AIAA/ASME/SAE/ASEE Joint Propulsion Conference \& Exhibit, pages 1-9, July 2011.

${ }^{14}$ Jones, C. M., Lee, J. G., and Santavicca, D. A. Closed-Loop Active Control of Combustion Instabilities Using Subharmonic Secondary fuel Injection. Journal of Propulsion and Power, 15(4):584-590, July 1999.
} 
${ }^{15}$ Tachibana, S., Zimmer, L., Kurosawa, Y., and Suzuki, K. Active control of combustion oscillations in a lean premixed combustor by secondary fuel injection coupling with chemiluminescence imaging technique. Proceedings of the Combustion Institute, 31(2):3225-3233, Jan. 2007.

${ }^{16}$ Altay, H. M., Hudgins, D. E., Speth, R. L., Annaswamy, A. M., and Ghoniem, A. F. Mitigation of thermoacoustic instability utilizing steady air injection near the flame anchoring zone. Combustion and Flame, 157(4):686-700, Apr. 2010.

${ }^{17}$ Zinn, B. and Neumeier, Y. An Overview of Active Control of Combustion Instabilities. 35th AIAA, Aerospace Sciences Meeting \& Exhibit, pages 1-18, Jan. 1997.

${ }^{18}$ Richards, G. A., Straub, D. L., and Robey, E. H. Passive Control of Combustion Instabilities in Stationary Gas Turbines. In Lieuwen, T. C. and Yang, V., editors, Combustion Instabilities in Gas Turbine Engines: Operational Experience, Fundamental Mechanisms, and Modeling, pages 533-579. American Institute of Aeronautics and Astronautics, Sept. 2009.

${ }^{19}$ Morehead, R. L. Project Morpheus Main Engine Development and Preliminary Flight Testing. 47th AIAA/ASME/SAE/ASEE Joint Propulsion Conference \& Exhibit, pages 1-7, July 2011.

${ }^{20}$ Richards, G. A., Straub, D. L., and Robey, E. H. Passive Control of Combustion Dynamics in Stationary Gas Turbines. Journal of Propulsion and Power, 19(5):795 - 810, Sept. 2003.

${ }^{21}$ Menon, S. and Ben Zinn, T. Combustion Control. In Joslin, R. D., Miller, D. N., and Lu, F. K., editors, Fundamentals and Applications of Modern Flow Control, pages 321-351. Progress in Astronautics and Aeronautics, Nov. 2009.

${ }^{22}$ McManus, K. R., Vandsburger, U., and Bowman, C. T. Combustor Performance Enhancement Through Direct Shear Layer Excitation. Combustion and Flame, 82:75-92, Jan. 1990.

${ }^{23}$ Paschereit, C. O. and Gutmark, E. Combustion Instability and Emission Control by Pulsating Fuel Injection. Journal of Turbomachinery, 130:1-8, Jan. 2008.

${ }^{24}$ Shcherbik, D., Lubarsky, E., Neumeier, Y., Zinn, B. T., McManus, K., Fric, T. F., and Srinivasan, S. Suppression of Instabilities in Gaseous Fuel High-Pressure Combustor Using Non-Coherent Oscillatory Fuel Injection. Proceedings of ASME Turbo Expo 2003 Power for Land, Sea, and Air, pages 1-10, June 2003.

${ }^{25}$ Bennewitz, J. W., Lineberry, D. M., and Frederick, R. A. Investigation of a Single Injector with Applied High Frequency Pressure Disturbances For Applications To Liquid Rocket Engine Combustion Instabilities. 49th AIAA Joint Propulsion Conference, pages 1-11, July 2013.

${ }^{26}$ Bennewitz, J. W., Lineberry, D. M., and Frederick, R. A. Application of High Frequency Pressure Disturbances as a Control Mechanism for Liquid Rocket Engine Combustion Instabilities. 49th AIAA/ASME/SAE/ASEE Joint Propulsion Conference, pages 1-11, July 2013.

${ }^{27}$ Schadow, K. C., Gutmark, E., and Wilson, K. J. Active Combustion Control in a Coaxial Dump Combustor. Combustion Science and Technology, 81(4-6):285-300, Feb. 1992.

${ }^{28}$ McManus, K. R. and Bowman, C. T. Effects of Controlling Vortex Dynamics on the Performance of a Dump Combustor. Twenty-Third Symposium (International) on Combustion/The Combustion Institute, 23(1):1093-1099, Jan. 1991.

${ }^{29}$ Guyot, D., Paschereit, C. O., and Raghu, S. Active Combustion Control Using a Fluidic Oscillator for Asymmetric Fuel Flow Modulation. International Journal of Flow Control, 1(2):155-166, July 2009.

${ }^{30}$ Raghu, S. Feedback-free fluidic oscillator and method. U.S. Patent, July 2001.

${ }^{31}$ Gregory, J. W., Sullivan, J. P., Raman, G., and Raghu, S. Characterization of the Microfluidic Oscillator. AIAA Journal, 45(3):568-576, Mar. 2007.

${ }^{32}$ Meier, E. and Heister, S. D. Computational Characterization of the Feedback Free Fluidic Oscillator. 50th AIAA/ASME/SAE/ASEE Joint Propulsion Conference, pages 1-16, July 2014.

${ }^{33}$ Bidadi, S., Heister, S. D., and Matsutomi, Y. Computational and Experimental Study of Jet Interaction Fluidic Injectors. Atomization and Sprays, 21(2):127-138, Jan. 2011.

${ }^{34}$ Tomac, M. N. and Gregory, J. Jet Interactions in a Feedback-Free Fluidic Oscillator at Low Flow Rate. 43rd Fluid Dynamics Conference, pages 1-10, June 2013.

${ }^{35}$ Tomac, M. N. and Gregory, J. Frequency Studies and Scaling Effects of Jet Interaction in a Feedback-Free Fluidic Oscillator. 50th AIAA Aerospace Sciences Meeting including the New Horizons Forum and Aerospace Exposition, pages 1-15, Jan. 2012.

${ }^{36}$ Feldman, T. W., Harvazinski, M. E., Merkle, C. L., and Anderson, W. E. Comparison between simulation and measurment of self-excited combuistion instability. 48th AIAA/ASME/SAE/ASEE Joint Propulsion Conference \& Exhibit, July 2012.

${ }^{37}$ Yu, Y., Sisco, J. C., Rosen, S., Madhav, A., and Anderson, W. E. Spontaneous Longitudinal Combustion Instability in a ContinuouslyVariable Resonance Combustor. Journal of Propulsion and Power, 28(5):876-887, Sept. 2012.

${ }^{38}$ Yu, Y., O'Hara, L., Sisco, J., and Anderson, W. Experimental study of high-frequency combustion instability in a continuously variable resonance combustor (CVRC). 47th AIAA Aerospace Sciences Meeting Including The New Horizons Forum and Aerospace Exposition, Jan. 2009.

${ }^{39}$ Huang, C., Feldman, T. W., Talley, D. G., Anderson, W. E., Sankaran, V., Merkle, C. L., and Harvazinski, M. E. Combustion Instability Mechanisms in a Pressure-coupled Gas-gas Coaxial Rocket Injector. 49th AIAA/ASME/SAE/ASEE Joint Propulsion Conference, July 2013.

${ }^{40}$ Feldman, T. Unstable Combustion Processes for a Single Element Shear-Coax Injector in a Longiudinal Combustor. Master's Thesis, Purdue University, pages 1-128, May 2013.

${ }^{41}$ Yu, Y. C. Experimental and Analytical Investigations of Longitudinal Combustion Instability in a Continuously Variable Resonance Combustor (CVRC). Doctoral Dissertation, Purdue University, pages 1-218, Apr. 2009.

${ }^{42}$ Luke, E. A. A rule-based specification system for computational fluid dynamics. $\mathrm{PhD}$ thesis, Dec. 1999.

${ }^{43}$ Luke, E. A. Loci: A Deductive Framework for Graph-Based Algorithms. Third International Symposium, ISCOPE 99, pages 142-153, Dec. 1999.

${ }^{44}$ Tong, X.-L., Wu, J., Tang, L., Cinnella, P., and Luke, E. A. A chemically reacting flow solver for generalized grids. http://www.tetraresearch.com/locichem/about-locichem/, pages 1-18, Jan. 2003.

${ }^{45}$ Luke, E. A., Tong, X., Chamberlain, R., Wu, J., and Cinnella, P. CHEM 3.3: A Finite-Rate Viscous Chemistry Solver - The User Guide, Aug. 2014.

${ }^{46}$ Nichols, R. H. and Nelson, C. C. Applications of RANS/LES Turbulence Models. 41st Aerospace Sciences Meeting and Exhibit, pages 1-17, Jan. 2003.

${ }^{47}$ Menter, F. R. Influence of Freestream Values on k- $\omega$ Turbulence Model Predictions. AIAA Journal, 30(6):1657-1659, Oct. 1991. 
${ }^{48}$ Wilcox, D. C. Turbulence Modeling for CFD. DCW Industries, Jan. 1998.

${ }^{49}$ Warming, R. F. and Beam, R. M. An Implicit Factored Scheme for the Compressible Navier-Stokes Equations. AIAA Journal, 16(4):393-402, Apr. 1978.

${ }^{50}$ Balay, S., Abhyankar, S., Adams, M. F., Brown, J., Brune, P., Buschelman, K., Eijkhout, V., Gropp, W. D., Kaushik, D., Knepley, M. G., McInnes, L. C., Rupp, K., Smith, B. F., and Zhang, H. PETSc Web page. http://www. mcs .anl.gov/petsc, 2014.

${ }^{51}$ Balay, S., Abhyankar, S., Adams, M. F., Brown, J., Brune, P., Buschelman, K., Eijkhout, V., Gropp, W. D., Kaushik, D., Knepley, M. G., McInnes, L. C., Rupp, K., Smith, B. F., and Zhang, H. PETSc users manual. Technical Report ANL-95/11 - Revision 3.5, Argonne National Laboratory, 2014.

${ }^{52}$ Balay, S., Gropp, W. D., McInnes, L. C., and Smith, B. F. Efficient management of parallelism in object oriented numerical software libraries. In Arge, E., Bruaset, A. M., and Langtangen, H. P., editors, Modern Software Tools in Scientific Computing, pages 163-202. Birkhäuser Press, 1997.

${ }^{53}$ Westbrook, C. K. and Dryer, F. L. Simplified Reaction Mechanisms for the Oxidation of Hydrocarbon Fuels in Flames. Combustion Science and Technology, 27(1-2):31-43, July 1981.

${ }^{54}$ Harvazinski, M. E. Modeling Self-Excited Combustion Instabilities Using a Combination of Two and Three Dimensional Simulations. Doctoral Dissertation, Purdue University, pages 1-266, Apr. 2012.

${ }^{55}$ Heister, S. D., Anderson, W. E., and Sardeshmukh, S. V. Prediction of Combustion Instability with Detailed Chemical Kinetics. 53rd AIAA Aerospace Sciences Meeting, pages 1-19, Jan. 2015.

${ }^{56}$ Merkle, C. L., Harvazinski, M. E., and Anderson, W. E. Analysis of Self-Excited Combustion Instabilities Using Two- and ThreeDimensional Simulations. Journal of Propulsion and Power, 29(2):396-409, Mar. 2013.

${ }^{57}$ ANSA v13.2.3 User's Guide. BETA CAE Systems S.A., May 2012.

${ }^{58}$ Marcum, D. L. and Weatherill, N. P. A procedure for efficient generation of solution adapted unstructured grids. Computer Methods in Applied Mechanics and Engineering, 127:259-268, Jan. 1995.

${ }^{59}$ Weatherill, N. P. and Marcum, D. L. Unstructured Grid Generation Using Iterative Point Insertion and Local Reconnection. AIAA Journal, 33(9):1619-1625, Sept. 1995.

${ }^{60}$ Meier, E. J. Investigation of Combustion Control in a Dump Combustor Using the Feedback Free Fluidic Oscillator. Master's Thesis, Purdue University, Aug. 2015. 